\title{
Sulphonamide-induced 'Thymineless Death' in Escherichia coli
}

\author{
By R. THEN AND P. ANGEHRN \\ Department of Experimental Medicine, F. Hoffmann-La Roche and Co. Ltd, \\ Basle, Switzerland
}

(Received 23 October 1972)

\begin{abstract}
SUMMARY
The conditions for induction of thymine deficiency by sulphonamides and their effect on viability were investigated in Escherichia coli. In minimal medium, sulphonamides led to a slight decrease in the viable count over a prolonged length of time. This decrease was more pronounced in Casamino acid supplemented medium. Concentrations of as low as $\mathrm{I} \mu \mathrm{g} / \mathrm{ml}$ of sulphamethoxazole or some other sulphonamides killed up to $99.9 \%$ of bacteria within $4 \mathrm{~h}$ after manifestation of inhibition in media supplemented by Casamino acids and inosine. No strict relation was found between sulphonamide concentration and the number of surviving bacteria. In all experiments sulphonamides exerted their effects after a time lag of 3 to $4 \mathrm{~h}$. Addition of thymidine prevented death. Effects similar to those in media containing Casamino acids and inosine were demonstrated in growth medium containing human blood. The possible role of this kind of action of sulphonamides in chemotherapy is discussed.
\end{abstract}

\section{INTRODUCTION}

The sulphonamides are generally cited as classical examples of bacteriostatic drugs (Bünger, Diller, Führ \& Krüger-Thiemer, 196r; Seydel, 1966, 1968). The impairment of de novo folic acid synthesis by sulphonamides leads to a multiple deficiency affecting different biosynthetic pathways. These include the biosynthesis of thymidylate, inhibition of which specifically affects DNA synthesis. There exists a close relationship between the availability of thymine and viability, both in thymine auxotrophs (Cummings \& Mondale, 1967; Cummings \& Kusy, 1969, 1970; Deutch \& Pauling, 197I) and in bacteria treated with trimethoprim, a dihydrofolate reductase inhibitor (Angehrn \& Then, 1973). The action of sulphonamides and trimethoprim can be antagonized by the same compounds, known as non-competitive sulphonamide antagonists. The conditions for induction of specific thymine deficiency by sulphonamides and its effect on viability were therefore studied in more detail. The experiments demonstrated that under appropriate conditions which also seem to exist in human body fluids, sulphonamides exert a 'bactericidal' action which is due to thymine deficiency, as expected from results obtained with trimethoprim (Angehrn \& Then, 1973) and as already demonstrated with sulphanilamide (Cohen \& Barner, 1956).

\section{METHODS}

Strain. Escherichia coli $\mathrm{I} 346$, a sulphonamide-sensitive wild-type strain, which has already been described (Angehrn \& Then, 1973; Then \& Angehrn, 1973), was used throughout these investigations.

Culture conditions. Cultures were aerated in a shaking water-bath at $37^{\circ} \mathrm{C}$ in $30 \mathrm{ml}$ of minimal salts medium $\mathrm{M} 9$ at $\mathrm{pH}_{7.0}$ to 7.2 (Angehrn \& Then, 1973). To investigate the 


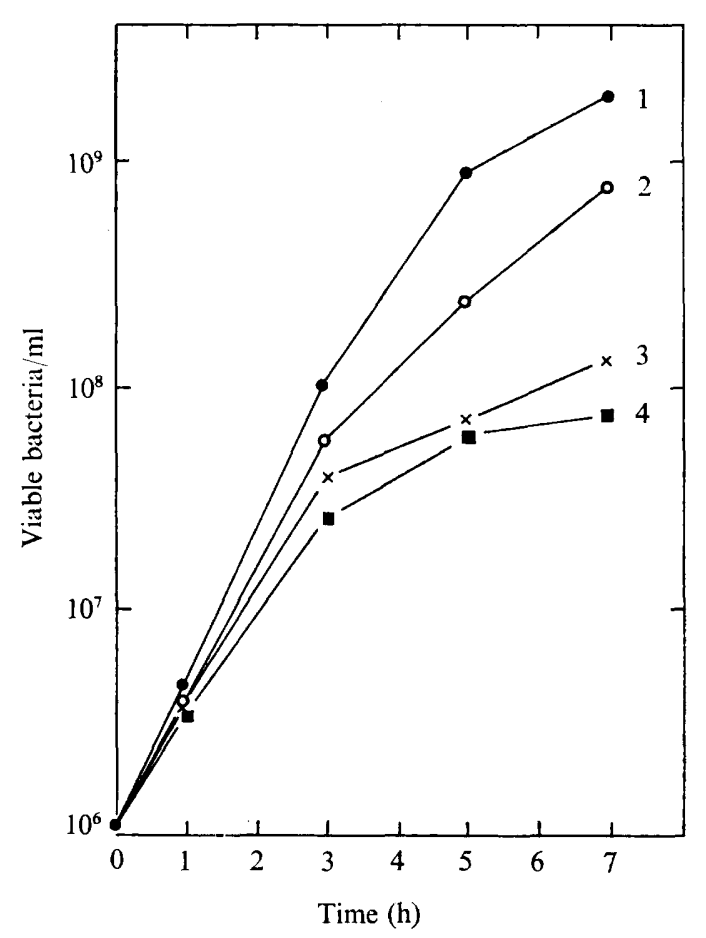

Fig. I. Inhibition of Escherichia coli growth in minimal medium $\mathrm{M} 9$ by sulphanilamide, added at time 0. I, Control; 2, I00 $\mu \mathrm{g}$ sulphanilamide $/ \mathrm{ml} ; 3,500 \mu \mathrm{g}$ sulphanilamide $/ \mathrm{ml}, 4$, $1000 \mu \mathrm{g}$ sulphanilamide/ml.

action of sulphamethoxazole (SMZ) in blood, $15 \mathrm{ml}$ of medium $\mathrm{M} 9$ was added to $15 \mathrm{ml}$ of whole human blood,which had been previously incubated for $30 \mathrm{~min}$ at $56^{\circ} \mathrm{C}$ to inactivate complement. Additions were made as indicated. Inocula of about $10^{4}$ and $10^{5}$ to $10^{6}$ organisms/ $\mathrm{ml}$ were used. All experiments were carried out with exponentially growing cultures. At the intervals indicated, subcultures were made on Difco blood agar base for viable counts.

Chemicals. Sulphamethoxazole ( $\mathrm{Na}$ salt), sulphisoxazole, sulphadoxine, sulphamonomethoxine and sulphanilamide were Roche products. Thymine, thymidine, cytidine, uridine, xanthine and xanthosine were purchased from Merck (Darmstadt, Germany), inosine and uracil from Fluka (Buchs, SG, Switzerland) and adenine, adenosine, guanine, guanosine, cytosine from Calbiochem (Los Angeles, California, U.S.A.).

\section{RESULTS}

Response of Escherichia coli to sulphonamides in minimal medium. Escherichia coli $\mathrm{I} 346$ responded to the addition of sulphanilamide, as demonstrated with other strains, by showing marked inhibition of growth only after several generations (Fig. I). Other sulphonamides tested, such as sulphamethoxazole (SMZ), sulphadoxine, sulphamonomethoxine and sulphisoxazole, were active in much lower concentrations, most probably due to a better uptake. In unsupplemented $\mathrm{M} 9$ medium no decrease in the viable count over a period of at least $9 \mathrm{~h}$ occurred. With SMZ, the number of bacteria did not further increase after about $4 \mathrm{~h}$. After $24 \mathrm{~h}$ the viable count was reduced to 2 to $20 \%$ with SMZ concentrations from 5 to $500 \mu \mathrm{g} / \mathrm{ml}$. 

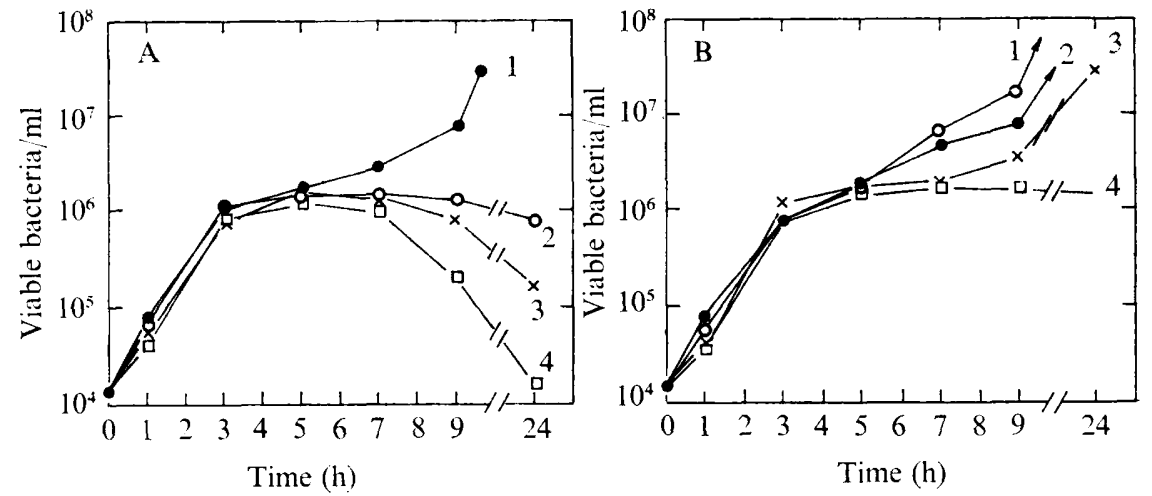

Fig. 2 (a) Effect of SMZ on growth of Escherichia coli in M 9 medium, supplemented with $0.1 \%$ Casamino acids. SMZ added at time o. I, $2 \mu \mathrm{g} \mathrm{SMZ} / \mathrm{ml} ; 2,5 \mu \mathrm{g} \mathrm{SMZ} / \mathrm{ml} ; 3$, $10 \mu \mathrm{g} \mathrm{SMZ} / \mathrm{ml}$; 4, $50 \mu \mathrm{g} \mathrm{SMZ} / \mathrm{ml}$. (b) Same experiment as in $(a), 50 \mu \mathrm{g}$ thymidine/ml added to each culture at $4.5 \mathrm{~h}$.

Effect of SMZ in amino acid supplemented medium. If medium $\mathrm{M}_{9}$ was supplemented with $0.1 \%$ of Casamino acids, SMZ concentrations of $\mathrm{I} 0$ and $50 \mu \mathrm{g} / \mathrm{ml}$ led to a slight reduction of the viable count within 7 to $8 \mathrm{~h}$ (Fig. $2 a$ ). Up to $3 \mathrm{~h}$ (about six generations) after addition of SMZ ( 2 to $50 \mu \mathrm{g} / \mathrm{ml}$ ) the growth rate was about that of the control (not shown in Fig. 2a), which is in accordance with the findings of others (Garrett \& Wright, 1967; Seydel, 1968). After $5 \mathrm{~h}$, the viable count decreased with SMZ concentrations higher than $5 \mu \mathrm{g} / \mathrm{ml}$. With $50 \mu \mathrm{g} \mathrm{SMZ} / \mathrm{ml}, 20 \%$ of the bacteria present at $5 \mathrm{~h}$ were still alive at $9 \mathrm{~h}$. In overnight cultures this figure dropped to I to I0 \%. With SMZ concentrations below $5 \mu \mathrm{g} / \mathrm{ml}$ the sulphonamide action could be overcome after temporary inhibition of growth. No decrease in the number of bacteria is seen even with high SMZ concentrations in the presence of thymidine (Fig. 2b).

Induction of thymine deficiency. For induction of specific thymine deficiency $\mathrm{M} 9$ medium was supplemented with $0.1 \%$ Casamino acids and inosine as a purine source. Other purine sources, such as adenine, guanine, adenosine, guanosine, xanthine and xanthosine, had about the same effects as inosine.

Under these conditions the viable count decreased after a lag of 3 to $4 \mathrm{~h}$ (Fig. 3). Concentrations between I and $50 \mu \mathrm{g} \mathrm{SMZ} / \mathrm{ml}$ killed up to $99.9 \%$ cells within $4 \mathrm{~h}$ after manifestation of growth inhibition. No strict relation between the sulphonamide concentration and the number of survivors could be found. Concentrations higher than $50 \mu \mathrm{g} \mathrm{SMZ} / \mathrm{ml}$ did not enhance the inactivation of bacteria, and the number of survivors after $24 \mathrm{~h}$ was generally higher than with lower sulphonamide concentrations (I to $50 \mu \mathrm{g} / \mathrm{ml}$ ). The decrease in viable counts was transient, independently of the SMZ concentration used (Fig. 4). In any case, inactivation of bacteria occurred after a time lag of at least $3 \mathrm{~h}$, corresponding to six generations, after sulphonamide addition. With inocula of $10^{6}$ bacteria $/ \mathrm{ml}$ inactivation only occurred after a greatly prolonged lag (up to $8 \mathrm{~h}$ ) and the reduction in viable counts was poor.

Other sulphonamides tested gave similar results to SMZ (Fig. 5). Concentrations of I to $5 \mu \mathrm{g}$ sulphadoxine/ml, sulphamonomethoxine and sulphisoxazole were also sufficient to induce cell death. For sulphanilamide, however, a concentration of about $500 \mu \mathrm{g} / \mathrm{ml}$ was necessary to produce an equal inactivation. With $200 \mu \mathrm{g} / \mathrm{ml}$ a light inactivation was seen. 


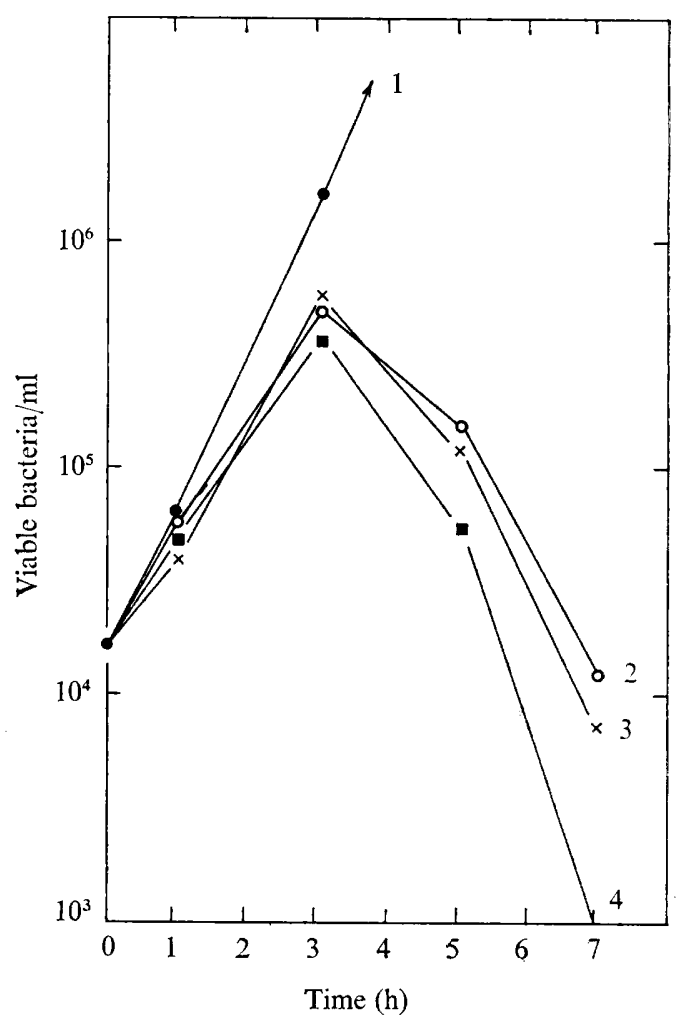

Fig. 3. Induction of death in Escherichia coli in minimal medium M 9, supplemented by $0.1 \%$ Casamino acids and inosine $(50 \mu \mathrm{g} / \mathrm{ml})$. SMZ added at time 0 . I, Control; $2,2 \mu \mathrm{g} \mathrm{SMZ} / \mathrm{ml}$; 3, $5 \mu \mathrm{g} \mathrm{SMZ} / \mathrm{ml} ; 4$, io $\mu \mathrm{g} \mathrm{SMZ} / \mathrm{ml}$.

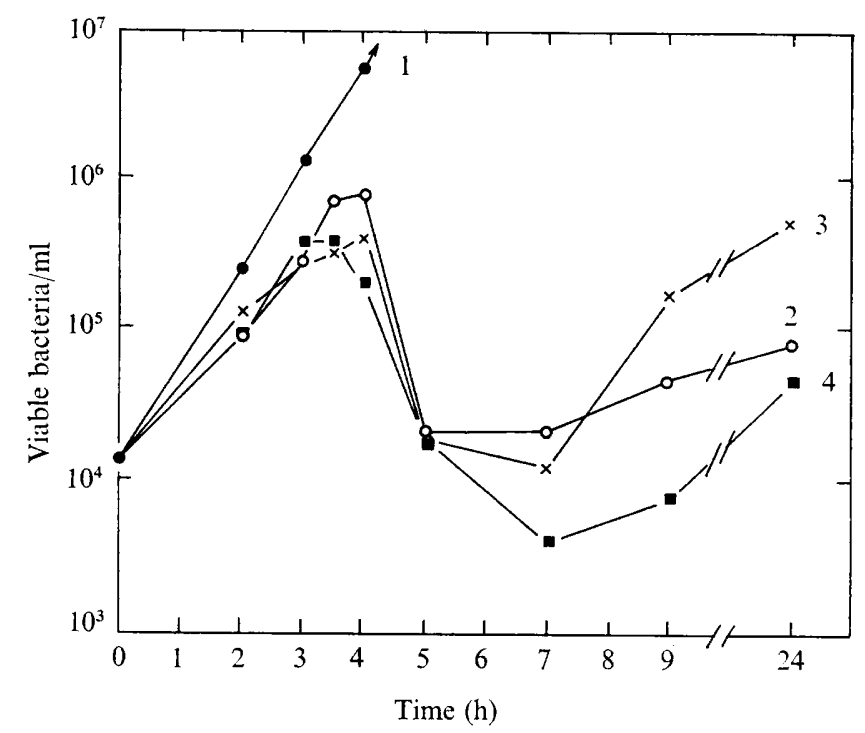

Fig. 4. Transient state of Escherichia coli inactivation by SMZ in minimal medium M 9, supplemented by $0.1 \%$ Casamino acids and inosine $(50 \mu \mathrm{g} / \mathrm{ml})$. SMZ added at time 0 . I, Control; 2, $10 \mu \mathrm{g} \mathrm{SMZ} / \mathrm{ml} ; 3$, $100 \mu \mathrm{g} \mathrm{SMZ} / \mathrm{ml} ; 4,500 \mu \mathrm{g} \mathrm{SMZ} / \mathrm{ml}$. 


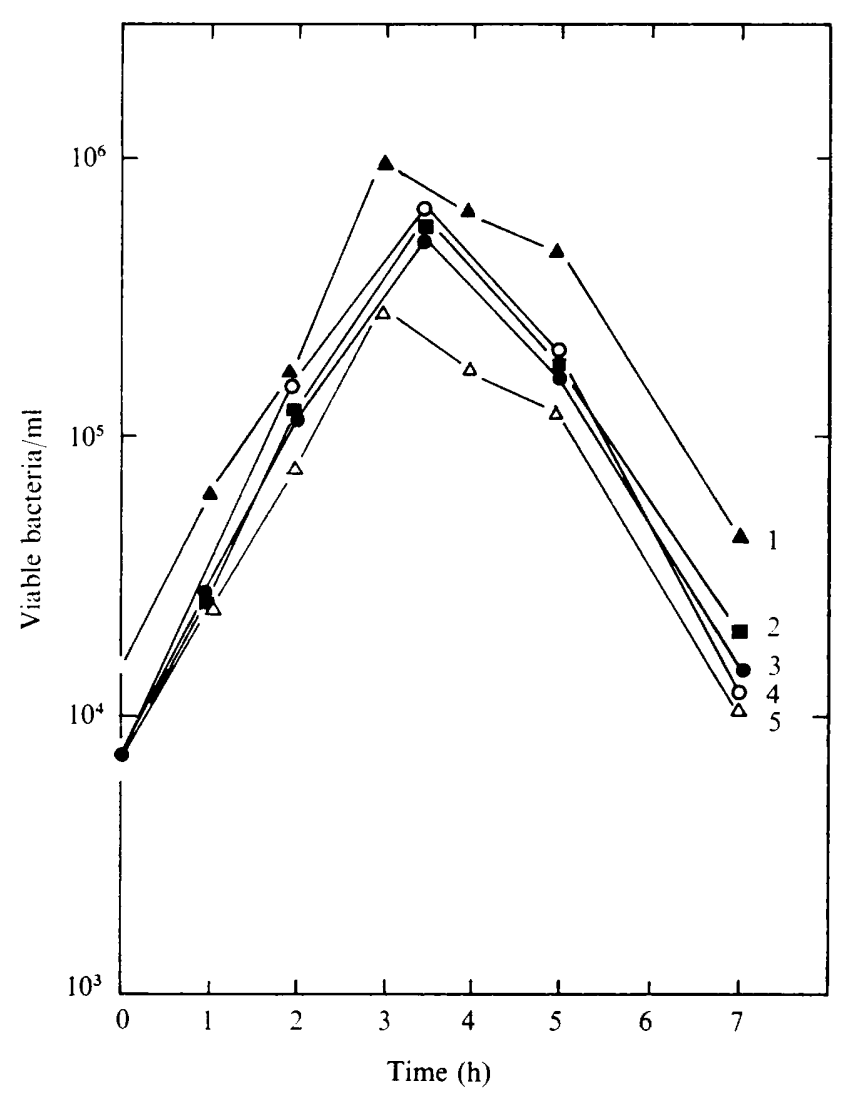

Fig. 5. Induction of death in Escherichia coli by different sulphonamides. Minimal medium $\mathbf{M} 9$, supplemented by $0.1 \%$ Casamino acids and inosine $(50 \mu \mathrm{g} / \mathrm{ml})$. Sulphonamides added at time 0 . I, $10 \mu \mathrm{g}$ Sulphisoxazole $/ \mathrm{ml} ; 2,5 \mu \mathrm{g} \mathrm{SMZ} / \mathrm{ml}$; $3,5 \mathrm{~g}$ sulphadoxine $/ \mathrm{ml}$; $4,5 \mu \mathrm{g}$ sulphamonomethoxine $/ \mathrm{ml} ; 5,500 \mu \mathrm{g}$ sulphanilamide $/ \mathrm{ml}$.

Cohen \& Barner (1956) used $2 \mathrm{mg} / \mathrm{ml}$ of sulphanilamide for demonstration of thymineless death in growth medium without thymine.

Prevention of cell inactivation by thymidine. Addition of thymidine during the inactivation phase in medium $\mathrm{M}_{9}$, containing Casamino acids and inosine, resulted in rapid recovery and growth (Fig. 6). Neither uracil, cytosine, uridine, nor cytidine prevented inactivation by sulphonamides. Generally, the addition of thymidine led to a rapid stop of inactivation and growth was resumed without delay. In some experiments, however, a lag of 30 to $60 \mathrm{~min}$ after addition of thymidine was observed. This behaviour has not so far been explained. In medium M 9, supplemented by Casamino acids, the slight inactivation observed is also caused by thymine deficiency, though there remains a double deficiency for purines and thymine. Thymidine completely prevented a reduction in the viable count over $24 \mathrm{~h}$. In the presence of $50 \mu \mathrm{g} \mathrm{SMZ} / \mathrm{ml}$, for example, the number of bacteria remains constant in contrast to about $99 \%$ inactivation without thymidine (Fig. $2 b$ ).

The loss of viability in plain M 9 medium over a period of $24 \mathrm{~h}$ was likewise referable to thymine deficiency, since thymine prevented this inactivation (Table I).

Induction of thymine deficiency by SMZ in human blood. Effects similar to those in synthetic media were observed in a medium containing $50 \%$ human blood. A slow bactericidal 


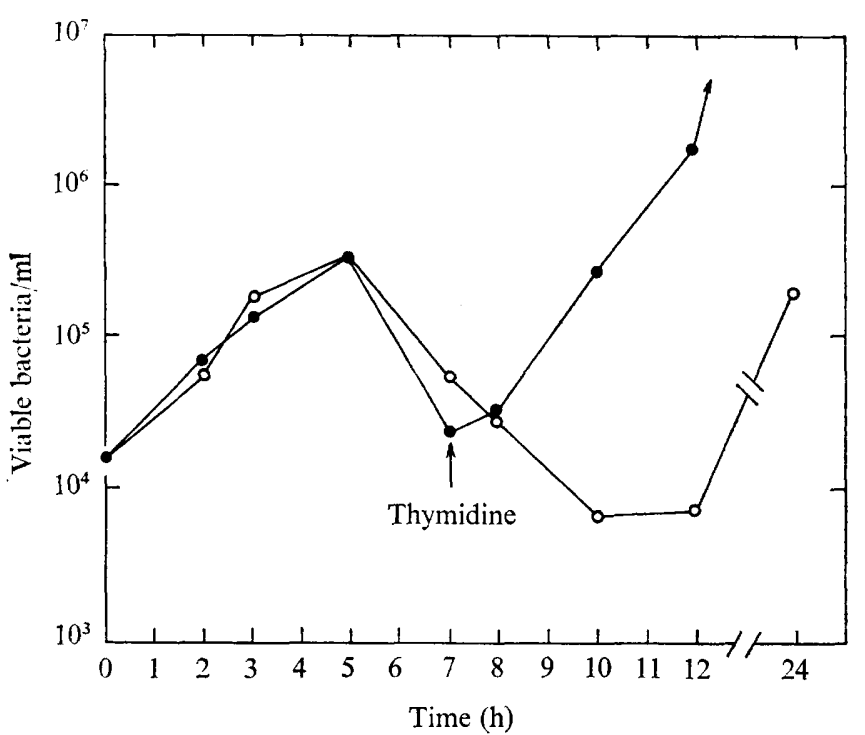

Fig. 6

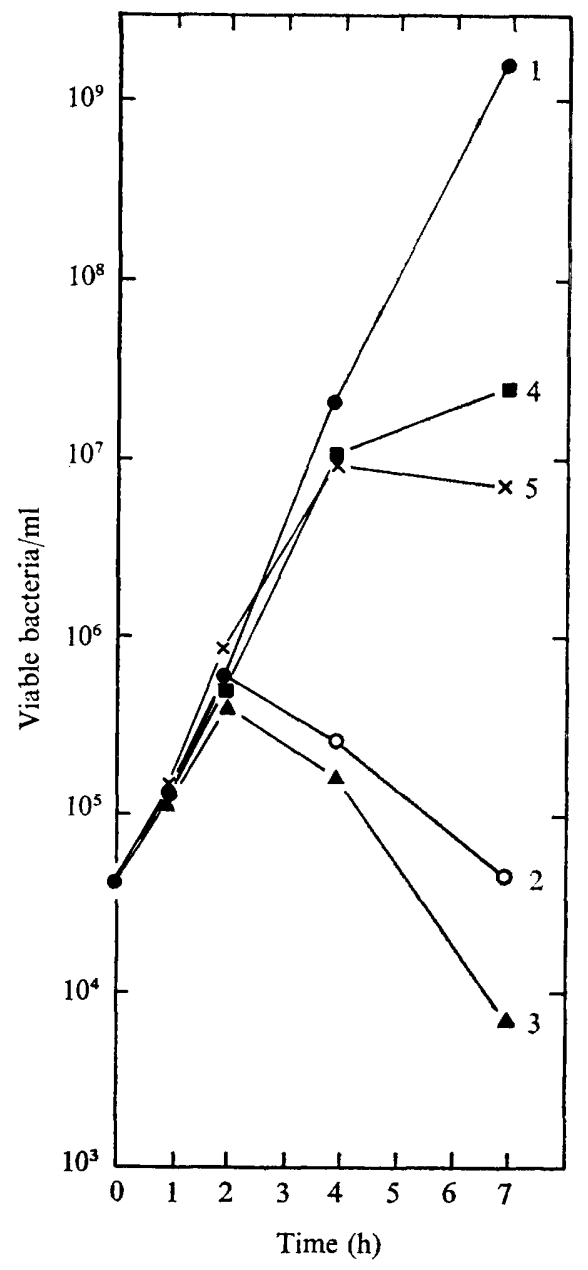

Fig. 7

Fig. 6. Reversal of SMZ-induced inactivation of Escherichia coli by thymidine, added at 7 h. Inactivation was induced in M 9 medium, containing $0.1 \%$ Casamino acids and $50 \mu \mathrm{g}$ inosine $/ \mathrm{ml}$. $\mathrm{SMZ}($ Io $\mu \mathrm{g} / \mathrm{ml})$ added at time 0 .

Fig. 7. Inactivation of Escherichia coli by SMZ in M 9 medium containing $50 \%$ human blood, and influence of thymine. SMZ and thymine added at time 0 . Blood was heated $30 \mathrm{~min}$ at $56^{\circ} \mathrm{C}$ before use. I, Control; 2, I $\mu \mathrm{g} \mathrm{SMZ} / \mathrm{ml} ; 3,20 \mu \mathrm{g} \mathrm{SMZ} / \mathrm{ml} ; 4, \mathrm{I} \mu \mathrm{g} \mathrm{SMZ} / \mathrm{ml}$ and $25 \mu \mathrm{g}$ thymine $/ \mathrm{ml}$ added; $5,20 \mu \mathrm{g} \mathrm{SMZ} / \mathrm{ml}$ and $25 \mu \mathrm{g}$ thymine/ml added.

Table I. Influence of thymine $(50 \mu \mathrm{g} / \mathrm{ml})$ on the viable count in $M 9$ medium after $24 h$, with different $S M Z$ concentrations (thymine added 7 h after $S M Z$ )

$\begin{array}{ccccc}\begin{array}{c}\mathrm{SMZ} \text { concn } \\ (\mu \mathrm{g} / \mathrm{ml})\end{array} & \text { Thymine } & \begin{array}{c}\text { No. of bacteria } \\ 7 \mathrm{~h} \text { after SMZ }\end{array} & \begin{array}{c}\text { No. of bacteria } \\ 24 \mathrm{~h} \text { after SMZ }\end{array} & \begin{array}{c}\text { Survivors } \\ (\%)\end{array} \\ 10 & - & 2.8 \times 10^{5} & 6.0 \times 10^{4} & 22 \\ 50 & - & 5.3 \times 10^{5} & 9.6 \times 10^{4} & 18 \\ 100 & - & 6.4 \times 10^{5} & 1 \cdot 5 \times 10^{5} & 24 \\ 10 & + & 3.0 \times 10^{5} & 4.7 \times 10^{5} & 160 \\ 50 & + & 3.6 \times 10^{5} & 4.6 \times 10^{5} & 130 \\ 100 & + & 4.4 \times 10^{5} & 1 \cdot 2 \times 10^{6} & 270\end{array}$


reaction took place after a lag phase of about $\mathrm{I} 20 \mathrm{~min}$, a period corresponding to three to four generations (Fig. 7). This reaction occurred with sulphonamide concentrations which are easily obtained in the blood after administration of therapeutic doses of sulphonamides. The bactericidal effect was, however, not as marked as with trimethoprim. The decrease in viable count could be prevented by addition of thymine.

\section{DISCUSSION}

It is generally assumed that sulphonamides have a bacteriostatic effect (see, for example, Bünger et al. 1961; Seydel, 1966, I968). An explanation for this type of action would be the gradual cessation of growth, which may be without lethal consequences. The synthesis of a false dihydrofolate precursor and the dilution of the existing tetrahydrofolate derivatives during growth are responsible for the lag between sulphonamide addition and the effects observed.

Investigations on different media have, however, shown that sulphonamides may also bring about a marked reduction in the viable count (Bushby \& Hitchings, I96I; Woods, 1962; Garrett \& Wright, I967). In the past this fact seems not to have been regarded as very important. The present studies show that this inactivation of cells is always due to lack of thymidylate and that thymidine completely prevents a drop in the viable count. Though it is known that the utilization of exogenous thymine is limited by the availability of deoxyribose moieties, it was shown that at the concentration used thymine can fulfil the thymidylate requirement as well as thymidine (Table I, Fig. 7).

It was demonstrated that the 'bactericidal' action of sulphonamides can be increased considerably if the multiple deficiency caused by the sulphonamide is reduced to the single deficiency of thymine (Cohen \& Barner, I956). The 'bactericidal' action is therefore increased by gradual addition of amino acids and a purine source to the minimal medium. The simultaneously induced lack of amino acids and purines in unsupplemented minimal medium leads to a decrease in protein synthesis which counteracts the lethal consequences of the simultaneously induced thymine deficiency. This behaviour is consistent with what is known on the mode of action of trimethoprim (Angehrn \& Then, 1973; Then \& Angehrn, I973) and to findings during 'thymineless death' (Ganguli \& Bhattacharjee, I968; Cummings \& Kusy, 1969, I970). As stated by Cohen \& Barner (1956), a clear differentiation between a bacteriostatic and a bactericidal action breaks down under such circumstances. The formation of long filaments observed in bacteria exposed to sulphonamides (Neipp, Sackmann \& Tripod, 196I) is presumably also due to thymine deficiency, since the same phenomenon has been described in 'thymineless death' (Cummings \& Mondale, 1967) and folate deficiency in Lactobacillus casei (Streeter, O'Neill \& Shum, 1970). It was also observed with trimethoprim in our laboratory. The mode of inactivation is, however, not yet clear. Cell death occurred in the presence of very low sulphonamide concentrations such as $\mathrm{I} \mu \mathrm{g} \mathrm{SMZ} / \mathrm{ml}(3.6 \mu \mathrm{M})$. It is questionable whether such low concentrations lead to complete exhaustion of the tetrahydrofolate pool and, in consequence, to complete deprivation of thymidylate, as may be caused with trimethoprim. However, as previously demonstrated (Deutch \& Pauling, I97I), thymineless death is not restricted to a complete thymine deprivation but may also occur in the presence of limiting concentrations of thymine. A leaky block in dihydrofolate synthesis may therefore explain the transient phase of inactivation. Other effects, not completely understood, may play a certain role - for example, the size of the inoculum.

One could also expect a higher inactivation rate by increasing the sulphonamide concen- 
tration. This is, however, only true over a limited range. The most effective inactivation was obtained with SMZ concentrations between 5 and $50 \mu \mathrm{g} / \mathrm{ml}$, which kills about $99.9 \%$ of the bacteria within $4 \mathrm{~h}$ after inhibition became manifest. Higher SMZ concentrations were less effective for induction of death. These results support the findings of Garrett \& Wright (1967), who stated that the death rate of organisms completely inhibited by sulphonamides does not seem to be strictly dependent on sulphonamide concentration. The apparent contradiction may be caused by an increasing inhibition of syntheses other than that of thymidylate, as was already mentioned, especially that of formylmethionyl-tRNA (Adams \& Capecchi, 1966; Capecchi, I966; Clark \& Marcker, I966), which cannot be exogenously supplied.

The question arises as to how far these findings are valid for the action of sulphonamides during sulphonamide treatment of infections. It was demonstrated that the composition of the human blood fluid seems to be well adapted to supporting a 'bactericidal' action, since it contains amino acids and purines, but obviously only limited concentrations of thymine in an available form. The effects demonstrated may therefore play a certain role in vivo and also serve to explain the often high effectiveness of sulphonamides. One aspect may support this assumption. Sulphonamides are relatively ineffective in purulent wounds, where the liberation of thymine from nucleic acid material would prevent the inactivation of bacteria (Woods, 1962).

We are grateful to $\mathrm{Dr}$ A. Schocher for valuable discussion during preparation of the manuscript, and to Mrs D. Bürgin and Mr P. Kölliker for skilful performance of the experiments.

\section{REFERENCES}

AdAMS, J. M. \& CAPECCHI, M. R. (I966). $N$-formylmethionyl-sRNA as the initiator of protein synthesis. Proceedings of the National Academy of Sciences of the United States of America 55, I47-155.

Angehrn, P. \& Then, R. (1973). Nature of trimethoprim-induced death in Escherichia coli. ArzneimittelForschung (Drug Research) (in the press).

Bünger, P., Diller, W., FüHR, J. \& KRÜGER-ThIEMER, E. (I96I). Vergleichende Untersuchungen an neueren Sulfonamiden. Arzneimittel-Forschung (Drug Research) II, 247-255.

Bushby, S. R. M. \& Hrtchings, G. H. (I968). Trimethoprim, a sulphonamide potentiator. British Journal of Pharmacology and Chemotherapy 33, 72-90.

CAPECCHI, M. R. (I966). Initiation of E. coli proteins. Proceedings of the National Academy of Sciences of the United States of America 55, I517-1524.

ClARK, B. F. C. \& MARCKer, K. A. (1966). The role of $N$-formyl-methionyl-sRNA in protein biosynthesis. Journal of Molecular Biology 17, 394-406.

COHEN, S. S. \& BARNer, H. D. (1956). Studies on the induction of thymine deficiency and on the effects of thymine and thymidine analogues in Escherichia coli. Journal of Bacteriology 7x, 588-597.

Cummings, D. J. \& Kusy, A. R. (1969). Thymineless death in Escherichia coli: inactivation and recovery. Journal of Bacteriology 99, 558-566.

Cummings, D. J. \& Kusy, A. R. (1970). Thymineless death in Escherichia coli: deoxyribonucleic acid replication and the immune state. Journal of Bacteriology ro2, 106-I 7.

Cummings, D. J. \& Mondale, L. (1967). Thymineless death in Escherichia coli: strain specificity. Journal of Bacteriology 93, 1917-1924.

Deutch, C. E. \& Pauling, C. (I97I). Survival and macromolecular synthesis during incubation of Escherichia coli in limiting thymine. Journal of Bacteriology 106, 197-203.

GaNGUl, N. \& BhatTaChaRJEe, S. B. (I968). Influence of chloramphenicol on thymineless death in bacteria. Biochimica et biophysica acta 169, 545-547.

GARRETT, E. R. \& WRIGHT, O. K. (1967). Kinetics and mechanisms of action of drugs on microorganisms. VI. Quantitative adherence of sulphonamide action on microbial growth to a receptor-site model. Journal of Pharmaceutical Sciences 56, 1576-1585. 
NeipP, L., SackmanN, W. \& Tripod, J. (196I). Some new trends in the field of experimental research on sulphonamides. Antibiotica et Chemotherapia 9, pp. 19-82.

SeYdeL, J. K. (1966). Molekulare Grundlagen der Sulfonamidwirkung. Arzneimittel-Forschung (Drug Research) I6, I447-1453.

SEYDEL, J. K. (1968). Sulfonamides, structure-activity relationship and mode of action. Journal of Pharmaceutical Sciences 57, I455-1478.

Streeter, A. M., O’Neill, B. J. \& Shum, H. Y. (1970). Folic acid deficiency in Lactobacillus casei. Pathology 2, $217-22 \mathrm{I}$.

Then, R. \& ANGehrn, P. (1973). Effects of trimethoprim on Escherichia coli under limited nutrition. Arzneimittel-Forschung (Drug Research) (in the press).

Woods, D. D. (1962). The biochemical mode of action of the sulphonamide drug. Journal of General Microbiology 29, 687-702. 